\title{
Research report: Experience of food insecurity and its effect on the psychosocial well-being of school-aged children in Damot Gale Woreda, South Ethiopia
}

\author{
Mesfin Balgu Tito*, Habtamu Wondimu \\ Department of Psychology, Arba Minich University, Arba Minich, Ethiopia \\ Email address: \\ mtito2005@gmail.com (M. B. Tito), mesfinbalgutito@yahoo.com (M. B. Tito)
}

\section{To cite this article:}

Mesfin Balgu Tito, Habtamu Wondimu. Research Report: Experience of Food Insecurity and Its Effect on the Psychosocial Well-Being of School-Aged Children in Damot Gale Woreda, South Ethiopia. Psychology and Behavioural Sciences. Vol. 3, No. 5, 2014 , pp. 158-170. doi: 10.11648/j.pbs.20140305.13

\begin{abstract}
This study aimed to describe the psychosocial experience of children living in food insecure family. Among the 328 total population, one hundered (100) are involved in the study. These participants were only involved in the quantitative data gathering process. Additionally, 28 participants are involved in the semi-structured interview and focus group discussion. Mixed approaches (quantitative and qualitative methods) has employed in the study. Descriptive statistics like percentage, mean and standard deviation; and independent $\mathrm{t}$ - test used to analyze the quantitative data, whereas summarization and direct quoting used to analyze the qualitative data. Children in food insecure households have common problems like - aggressive behaviors, misconduct behaviors (i.e. cheating, stealing and disrespecting the elders), depression, feeling shame and poor interpersonal relationship. Additionally, children experience behaviors like - gambling, robbery, murder or homicide, school absenteeism, hot emotionality, inferiority, insomnia, stigma and discrimination. The older children (13 - 18) are more experience depressive behavioral and interpersonal relationship problems than the younger children (6-12) are. Maternal depression, parenting style (autocratic parenting style), parental carelessness to fulfill children's basic needs, children's current dressing styles, health conditions; tasks, duties and responsibilities that are beyond the children's capacity are the basic reasons that push children to experience the psychological and social problems. Beside the physical consequences of food insecurity, it has great effect on the children's psychological and social wellbeing. Working in poverty reduction rather than heavily relying on food aids, using inclusive methods of research, using inclusive psychosocial care and support strategies, establishing community and institution based care and support and expert based intervention on the children's misconduct behaviors are suggested direction to overcome children's problems.
\end{abstract}

Keywords: Food Insecurity, School Aged Children, Psychosocial Well Being and Food Insecure Households

\section{Background}

Food is one of our most basic needs, along with oxgygen,water,and regulated body temperture. It is a basic necessity for human survival. But food is much more than just nutrients. Food is at the core of humans' cultural and social beliefs about what it means to nurture and be nurtured.The U.S Departement of Agriculture defined food security as access by all people all times to enough food for an active, healthy life and is one of several conditions necessary for a population to be healthy and well-nourished. Food insecurity, in turn, refers to limited or uncertain availability of nutritionally adequate and safe foods, or limited or uncertain ability to acquire food in socially acceptable ways (Cook and Jeng, 2009).

A numbers of studies have attempted to assess the effects of households food insecurity on the nutritional, physical and mental well being of children using household level measures of food insecurity. In short, these studies reported associations between household food insecurity and adverse emotional, behavioral, acadamic, and cognitive measures as well as poorer mental and physical quality of life measures among childern. Little if any research has been conducted to assess children's own perceptions or experience with food 
insecurity. An understanding of the experience of food insecurity by children is essential for better measures and assessment of the effect of food insecurity on children's health and quality of life (Pilgrim, 2010).

A growing body of research has examined the relationship between food insecurity and child development, and evidence suggests that food insecurity is directly associated with mental and psychosocial outcomes(Ryu, 2010). More specifically food - insecurity results in severe social, psychological and behavioral consequences. Food - insecure individuals may manifest feelings of alienation, powerlessness, stress and anxiety, and also they experience reduced productivity, reduced work and school performance (Gunderses and Kreider, 2009).

Researcher found that food insufficient children and teens were more likely to have difficulty getting along with other children and to have seen a psychologists (Nord et al., 2009). Additionally, a descriptive survey done in 180 preschool aged and 288 school aged children indicated that for both preschoolers and school aged children, severe child hunger was associated with higher levels of internalizing behavior problems. And after controlling for housing status, mother's distress, and stressful life events, severe child hunger was also associated with higher reported anxiety/ depression among school aged children (Weinreb, 2002).

On the other hand, a study by Connell et al. (2005) has reported that children in food insecured household experience psychological problems including shame or fear of being labeled as poor. Also children experience social aspects like social exclusion and weak interpersonal relationship. Forexample:- food insecure children have been found to experience difficulties in getting along with peers, depressive disorders, and suicidal ideation, and fatigue, irritability, and difficulty (Ashiabi, 2011).

Food insecured children experience various types of psychosocial and behavioral problems including higher levels of aggression, hyperactivity, and anxiety as well as passivity. And increased school absences, tardiness, and school suspension (Slack, 2004 ). A correlational study done in 942 participants shows that food hardships are positively associated with externalizing and internalizing behavior problems and with parenting stress and depression. Parenting stress and depression are positively associated with externalizing and internalizing behavioral problems of the children (Slack, 2004).

A longitudinal study done on the school aged children shows that, other things being equal, children who are poor are more likely than others to report having a difficult home life, to have negative attitude towards school, to feel isolated and anxious and to engage in anti - social and risky behaviour (Tomlinson et al., 2008).

Accumulating evidence suggests that, poor childern are typically rated by their parents and teachers as having more behavior problems than their peers. In childhood, this is reflected in elevated levels of externalizing problems, such as aggression and acting out, and internalizing problems, such as depression and anxiety; in adolescence and later adulthood, in higher rates of non marital fertility and criminal activity (Magnuson \& Votruba - Drzal, 2009).

Food hardship due to limited household resources is associated with greater numbers of behavioral problems in children, including hyperactivity and aggression as well as withdrawn behaviors. Food insecure children appear to have more difficulties getting along with their peers, increased odds of being suspended from school (Roche, 2002).

Similar with the above studies, the research indicated that adults in food insecure households are significantly more likely to exibits symptoms of depression than other adults. A sizeable body of research has found that parental depression is associated with children's interpersonal relationship. As the findings, children have poor interpersonal relationship with their peer groups and parents (cited in Bronte-Tinkew et al., 2008 pp. 16 - 17).

On the other hand, parents' social and economic resources can affect the quality and stability of their relationships with their children, and parent-children relationship affect children's emotional and children's interaction with their peer groups (Braveman et al., 2008).

Consistent with the above study, young people living in low - income households reported a stigma attached to their circumstances, which impacts on school and community involvement. And living on a low income can affect the quality of parent- child relationships, but the relationship between food insecurity and parenting is often misunderstood. While there is evidence that food insecurity affects parents' ability to manage stressful events, associations between household food insecurity and physically punitive parenting are still contested. A correlation has been identified between family income and children being removed from their parents' care (cited in Purutcuoglu \& Hablemitoglu, 2002 Pp. 21).

Research done by Robinson et al., (2005) on the re analysis of two qualitative research in Canada indicated that poor children feel deprived, part of the 'poor group' embarrassed, and hurt. Children do identify group membership but it is not used as a social resources, as it could be, but rather as a symbol of social segregation.

\section{Methodology}

Population: In this study children in food insecure households were included according to the data or stastistics of Woreda agricultural and rural office in 2010/11. These households were households who have school aged children and who are attending primary school (1-8 grade levels). The age limit of the population is based on WHO defintion of child (2000) and UN convention of child right (1990) ranged from 1-18 years old. However, the researcher has excluded all the preschool childern whose age is below six years and children who are attending their secondary school education.

Study design: The researcher has employed cross sectional survey.

Sample: Purposively two extremely food insecurity exposed villages were selected from Dmot Gale Woreda (DGW). 
Sample size: Among the total population (food insecure households) of 328, one hundered (100) were involved in this study. These participants were only involved in the quantitative data gathering process. One hundered school aged children in one hundered food insecure households were taken as the participants of this study. This is because participants are considered as homogeneous in their socioeconomic status (age, living standard, daily feeding habitat, health and other social care), education status (primary education) and the ecological setting. Beside the participants involved in the quantitative data collection 12 participants for the semi-strucured interview from the two villages i.e children in food insecure households (four), religion leaders(two), villages' adminstration bodies (two), community leaders (two), and teachers in the school (two) were involved. All participants in the semi - structured interview (SSI) were selected through purposive sampling. This is because these participants were expected to be rich in information and have more experience than the others.

Beside the interview two Focus Group Discussion (FGD) in each villages were conducted. In each villages there was a focus group discussion with the eight parents in the most food insecure households and eight children in the most food insecure households. Therefore, four FGDs were conducted in two villages in two groups. The selection of these households and children was done through purposive sampling. Because these households and children were considered as the most worst food insecurity experience in the villages.

Sampling techinques: The selection of the participants' parents was done through the stratification sampling methods. According to the information in the two villages, there are eight sub-villages in the two main villages. In the first village (Zegere) there are five sub-villages, where as there are three sub-villages in the second village (Obe jage). These subvillages were taken as strata for only the purpose of this study. Because there are different geographical boundaries in which these villages are componded. Therefore, in all stratas the propotional numbers of partcipants were assigned. After the participants were grouped in their stratas, random sampling (lottery) method was used to select the participants' households. This was done by using lists of households in villages. Meanwhile, the participant children in the selected household were selected through lottery sampling methods. This method was only applied in those households who have more than one children whose age is between $6-18$ years old.

Instrument development: In this study, close ended questionnaire, semi-structured interview and focus group discussion (FGD) were used. In the close ended questionnaires scales with slight correction for child depression (Weissman et al., 1980), feeling shame(Andrews et al, 2002), aggression (Emerson et al., 1994) and interpersonal relationship (Zimet et al., 1998) were used. And also the researcher has used scale for children's experience to food insecurity. And Child Food
Insecurity Scale (CFSS) by the U.S food insecurity scale for the children's food insecurity scale (2000) was used. In processes of tools development researcher has slightly modified items. Instruments were developed in the English version. However, after all suggestions and comments are given from the expertises and collegues, the last used tools were translated in to Woliategna language version. This is to solve some problems of language among the participants. English to Wolitiagna transilation was done by Wolitagna languge experts.

Data analysis : Descriptive and inferential stastistics were used. The descriptive staststics like percentage, mean and standard devation were used. These stastistics were used to describe children' experience of food insecurity, children's externalizing behaviors, internalizing behaviors and the interpersonal relationship. The inferential stastistics like independant t-test was used to observe the significant difference among different age groups. Along with the quantitative data analysis, summerization and description have made to analyze the qualitative data.

Reliability was investigated by using Cronbach's alpha, using SPSS 15 version. In the case of food insecurity scale, 9 items' internal reliability was equal to 0.59 cofficients of alpha, aggression scale 4 items' internal reliability was equal to 0.64 cofficients of alpha, interpersonal relationship scale 7 items' internal reliability was equal to was equal to 0.6 cofficients of alpha, deprssion scale 5 items' internal reliability is equal to 0.62 cofficients of alpha, and feeling shame scale 8 items' internal reliability was equal to 0.57 cofficients of alpha. Though the Cronbach alpha is not strong for all items, the researcher had no other option to use culturally related items.

Ethical consederation: Before starting the data collection, the researcher was strictly oriented and gave two days training for the field supervisors and data collectors. The field supervisor and data collectors are well oriented that the participants should be aware about the purpose of the study, and the importance of the study. During the interview and FGDs all flows of ideas were encouraged, apperciated and respected. Participants were informed that all participants have the right to talk whatever they felt and participants are well awared that participants have right to terminate their partcipation at the beginning and middle of the discussion if they do not want.to continue. After all the orintation are given, participants are asked to sign their informed consent. unfortunately, All of the participants were not willing to sign on the mannual, but they were volunteer to participate in the study. And the informed consent was obtained to post different photos and video were taken during the time of data collection.

\section{Results}


Table 1. Descriptive analysis of children's current status of food - insecurity

\begin{tabular}{|c|c|c|c|c|}
\hline Nos & Items & Response & Frequency & Percent $(100 \%)$ \\
\hline \multirow{2}{*}{1} & I worried whether our food would run out before our family got money to buy & yes & 62 & 62 \\
\hline & more & No & 38 & 38 \\
\hline \multirow{2}{*}{2} & \multirow{2}{*}{ We couldn't afford to eat balanced meals in our family } & Yes & 68 & 68 \\
\hline & & No & 32 & 32 \\
\hline \multirow{2}{*}{3} & \multirow{2}{*}{$\begin{array}{l}\text { In the last } 3 \text { months, did you or family members in your household ever cut size } \\
\text { of your meals or skip meals because there wasn't enough money for food? }\end{array}$} & Yes & 59 & 59 \\
\hline & & No & 41 & 41 \\
\hline \multirow{2}{*}{4} & \multirow{2}{*}{ Did the above happen in every month? } & Yes & 86 & 86 \\
\hline & & No & 14 & 14 \\
\hline \multirow{2}{*}{5} & In the last three months, did you ever eat less than you felt you should because & Yes & 75 & 75 \\
\hline & there wasn't enough money to buy food? & No & 25 & 25 \\
\hline \multirow{2}{*}{6} & Sometimes people lose weight because they don't have enough to eat. In last 3 & Yes & 90 & 90 \\
\hline & months, did you lose weight because there wasn't enough food? & No & 10 & 10 \\
\hline \multirow{2}{*}{7} & Did the above hannen in every month? & Yes & 91 & 91 \\
\hline & Did the above happen in every month? & No & 9 & 9 \\
\hline \multirow{2}{*}{8} & In the last 3 months, did any of childern in your family ever skip meals because & Yes & 83 & 83 \\
\hline & there wasn't enough money for food? & No & 17 & 17 \\
\hline \multirow{2}{*}{9} & In the last 3 months, were the childern ever hungry but your family just couldn't & Yes & 65 & 65 \\
\hline & afford more food? & No & 35 & 35 \\
\hline \multirow{2}{*}{10} & Total (Average) & Yes & 75.44 & 75.44 \\
\hline & 10tal (Average) & No & 24.56 & 24.56 \\
\hline
\end{tabular}

The above results indicated that most of the participants have currently experience food - insecurity in their households.

Table 2. Children's experience of aggression

\begin{tabular}{|c|c|c|c|c|}
\hline Nos & Items & Response & Fequency & Percent(100\%) \\
\hline \multirow{2}{*}{1} & \multirow{2}{*}{ I get very angry and often lose my temper } & Yes & 77 & 77 \\
\hline & & No & 23 & 23 \\
\hline \multirow{2}{*}{2} & \multirow{2}{*}{ I am easily distracted. I find it difficult to conentrate } & Yes & 76 & 76 \\
\hline & & No & 24 & 24 \\
\hline \multirow{2}{*}{3} & \multirow{2}{*}{ I never forgive somebody who hurt or upset me } & Yes & 71 & 71 \\
\hline & & No & 29 & 29 \\
\hline \multirow{2}{*}{4} & \multirow{2}{*}{ I always face conflict with my peer groups } & Yes & 53 & 53 \\
\hline & & No & 47 & 47 \\
\hline \multirow{2}{*}{5} & \multirow{2}{*}{ Total ( Average ) } & Yes & 69.25 & 69.25 \\
\hline & & No & 30.75 & 30.75 \\
\hline
\end{tabular}

Table 3. Children's experience of conduct problems

\begin{tabular}{clccc}
\hline No & Items & Response & Frequency & Percent \\
\hline \multirow{2}{*}{1} & \multirow{2}{*}{ I am often accused of lying or cheating } & Yes & 65 & 65 \\
& & No & 35 & 35 \\
2 & I take things that are not mine from home, schools or elsewhere & Yes & 75 & 75 \\
& & No & 25 & 25 \\
\multirow{2}{*}{3} & \multirow{2}{*}{ I don't care for elders other adults } & Yes & 71 & 29 \\
\hline
\end{tabular}

The table 2, indicates that majority of the participants have experience aggeression or aggressive behaviors. On the other hand, the table 3 , indicates that most of the participants have experience some conduct problems (i.e stealing, cheating and disrespecting elders ).

The above quantitative result is supported by the qualitative results. Forinstance:- most of the participants involved in the semi - structured interview and Focus group discussion (FGD) agreed that most of the children's in food insecure households experience the socially violent behaviors The most frequently happening behaviors like hot emotionality (unable to control thier emotion), lack of Patience, hurting their peers and community, and conflict with their peers, parents and other community members. These all problems are suggested as the means for children to develop aggressive behaviors. This is the fact that children in food insecure households commonly engaging in different forms of anti social behaviors like stealing, gambling, and robbery. The participants underlined that children's behavioral experience is linked with their parental aggression and parental depression due to the shortage of food at home and lack of money to buy food.

According to children involved in the semi - structured interview, children in food insecure households experience the frequent conflict with their peer groups and with different persons. Children also forward that their friends try to 
undermine and want to marginalize them from the play grounds and also other social relationship ispects. Even some time children want to insult as poor and also want exert additional pressures on the poor children or children from the poor family. This also contributes its' own part in children's experience of aggressive behavior.

A child stated the reasons for conflict with their peers or others as, 'My friends always insult me as donkey. When I ask them why? They reply that because their is no difference between poor and donkey. Therefore, your parents are poor, so you should carry other children in your sholder. This is the fact that I always feel angry and get conflict with my friends "( a 16 years old child).

According to the children's reponse, there are various factors that lead children to be emotionally aggressive. Forinstance :- peer groups negative attitude towards poor children, frequent conflicts within the family members due to the shortage of food, shortage of food to eat after and before the school and parenting style in the family (autocratic or dictatorship).

In the semi - structured interview a 15 years old young child shares his experience as : 'I know it is difficult to be free from thinking the food problem. This is fact that when the chronic food problems in our home come to disturbe my mind, I feel angry and I will be trusted if I bit or hurt my friends or other persons". Similar with the above idea, in the semi - structured interivew a 13 years old child added his lived experience as; 'In our school and in our neighbor too, my friends are not willing to play with me. They have no good feeling to me and our family too. Because their parents always want to marginalize us. I don't feel cool because I know my friends want to isolate me because our parents are poor. For this reason, I am always getting angry and also I always want to get conflict with my friends".

In the FGD most of the participants argued that parental food insecurity enforce children to be emtionally hot, aggressive and nervious. During the discusion the most repeatedly raised idea like 'an intention to prevent themselves from peer group moral attack, children develop emotionally hot behaviors."

Most of the childern participated in the semi - structured interview and focus group discussion agreed that 'most of the time before school or after the school children have little chance to get their meals.' A 44 years old teacher share his knowledge to children's experience as: ''Look, children some time go to school with out their meals. But it is not only the case, children have nothing to eat after the school. Feeling of hungry leads children to be angry and emotionally hot."

\section{Children's Experience of Conduct Problems}

Parents participated in the FGD agreed that most of the children in the poor households engaged in anti social behaviors or show some conduct problems. Children experience gambling, cheating, participating in the criminal activities and disrespecting their elders. According to the participants, children experience misconduct behaviors because families are unable to carry out their parental responsibilities and duties.

During the time of an interview a 48 years old community leader remembered his eposide as: 'I have a truma that I lost one of our known community member who was killed in last year by those gangesters from the poor households. Because these children are not obey to their parents and act out the norms of the community. Parental carelessness contributes a lot to children to be orderliness. The police investigation indicated that the criminals are spent their full time in playing gambling before killing a person. It is a big problem and needs serious intervention".

And also a key informant in the semi - structured interview added his experience that "A lot of time I observed children in food insecure households experience various forms of misconduct behaviors in the classroom (i.e frequent conflict with their friends, frequent absentism, stealing their friends learning materials and participating in the gambling"'(a 32 years old teacher).

A 46 years old adult agreed with the ideas of a 32 years old teacher. He revealed that sometimes children in food secure households are also experience misconduct behaviors, but it is extermely different. Poor management of the children's behavior in households is suggested to be the reason for experssion of behavioral aggression and misconduct behaviors of the children in the poor households or food insecured households. Some time children in food secure households too experience misconduct behaviors. But it is not serious as children in food insecure households.

Table 4. Children's experience of depression

\begin{tabular}{|c|c|c|c|c|}
\hline No & Items & Response & Frequency & Percent \\
\hline \multirow{2}{*}{1} & \multirow{2}{*}{ I feel like I couldn't pay attention to what I was doing } & Yes & 71 & 71 \\
\hline & & No & 29 & 29 \\
\hline \multirow{2}{*}{2} & \multirow{2}{*}{ I don't feel something good was going to happen in our family } & Yes & 57 & 57 \\
\hline & & No & 43 & 43 \\
\hline \multirow{2}{*}{3} & \multirow{2}{*}{ I felt like things I did before didn't work out because I haven't done it well } & Yes & 74 & 74 \\
\hline & & No & 26 & 26 \\
\hline \multirow{2}{*}{4} & \multirow{2}{*}{ I didn’t sleep well in the last two days because I haven't eat enough food } & Yes & 77 & 77 \\
\hline & & No & 23 & 23 \\
\hline \multirow{2}{*}{5} & \multirow{2}{*}{ I felt people didn't like me because our family are poor } & Yes & 86 & 86 \\
\hline & & No & 14 & 14 \\
\hline \multirow{2}{*}{6} & \multirow{2}{*}{ Total ( Average) } & Yes & 73 & 73 \\
\hline & & No & 27 & 27 \\
\hline
\end{tabular}


The above table indicates that most of the participants in food insecure household have experience depression.

The above statement is supported by the information obtained in the semi - structured interview and focus group discussion. Mainly, the informations indicated that children are want to be alone, emotional distress, not motivated to go school, hopeless and lack of concentration to what they are doing. Children have given various types of tasks, duties and responsibilities in their households that are beyond their capacity to carry out in their age level. This is also the other reason that exposed children to feel depression in their life (religious leader).

Those children who are in the primary school are more suffered food problems in their households than children in Junior school. This is the fact that young children have experience severe psychosocial problems than older children. Forinstance, children in the primary school more experience internalizing behavioral problems like depression, feeling shame or being labeled as poor than the older children. The older children easily can obtain food from their friends and other persons through socially unacceptable ways or acceptable ways, but it is difficult for the younger one (households participated in the focus group discussion).

Mainly shortage of food to eat in the their home, frequent illness of children or other members of parents due to food problems, lack of dresses, parental conflict, harsh or autocratic type of parenting, unable to attend school due to the lack of learning materials and peer group alienation are some of the reasons that push the children to experience depression (children in SSI).

In some instance this idea is corelated with the idea that obtained from a 13 years old child in the SSI "I feel not good in my dresses. My friends have an intersting dresses. But mine is an 'ugly' one. Therefore, don't you think this is factor for feeling depression?".

On the other hand, in the sem - structure interview a 15 years old child associates the problems with the maternal depression. In her experience her mother always feel anxious about the problems of food in the household. Therefore, every one in the household have been anxious to get daily meal. She further shares her experience as: "Always in our family our mother is worring and disturbing herself becuase of the chronic food problem in our home. Look at, your Mom is worring and disturbing herself to you, how do you think that you are free to feel pain?. For me it is impossible. Therefore, her disturbance affect us to be angry, worry and thinking about the problems with her".

In additionally, a 17 years old child shares his experience of depression as: "Some times I feel sucide. I feel it is a better solution in my life literally it means that 'Hagapee hayiqayichina gadda qopiyssi' because the food problem in our family is chronic. Therefore, I never think this problem will be solved".

Table 5. children's experience of feeling shame

\begin{tabular}{|c|c|c|c|c|}
\hline No & Items & Response & Frequency & Percent \\
\hline \multirow{2}{*}{1} & \multirow{2}{*}{$\begin{array}{l}\text { Have you felt ashamed of the sort of person you are from the family } \\
\text { you have? }\end{array}$} & Yes & 84 & 84 \\
\hline & & No & 16 & 16 \\
\hline \multirow{2}{*}{2} & \multirow{2}{*}{ Have you felt ashamed when you failed in a competitive situation? } & Yes & 72 & 72 \\
\hline & & No & 28 & 28 \\
\hline \multirow{2}{*}{3} & \multirow{2}{*}{ Have you wanted to hide your parents problem to your friends? } & Yes & 69 & 69 \\
\hline & & No & 31 & 31 \\
\hline \multirow{2}{*}{4} & \multirow{2}{*}{ Do you feel shame if someone insult you as poor? } & Yes & 55 & 55 \\
\hline & & No & 45 & 45 \\
\hline \multirow{2}{*}{5} & \multirow{2}{*}{$\begin{array}{l}\text { Have you worried about what other people think of your parents } \\
\text { conditions? }\end{array}$} & Yes & 81 & 81 \\
\hline & & No & 19 & 19 \\
\hline \multirow{2}{*}{6} & \multirow{2}{*}{$\begin{array}{l}\text { Have you felt ashamed of your body or any part of it or your current } \\
\text { weight and height? }\end{array}$} & Yes & 71 & 71 \\
\hline & & No & 29 & 29 \\
\hline \multirow{2}{*}{7} & \multirow{2}{*}{ Have you feel discomfort when someone asks you about your family? } & Yes & 74 & 74 \\
\hline & & No & 26 & 26 \\
\hline \multirow{2}{*}{8} & \multirow{2}{*}{$\begin{array}{l}\text { Have you worried about what other people think of any of your personal } \\
\text { habits like dressing, feeding habits, etc? }\end{array}$} & Yes & 76 & 76 \\
\hline & & No & 24 & 24 \\
\hline \multirow{2}{*}{9} & \multirow{2}{*}{ Total ( Average ) } & Yes & 72.75 & 72.75 \\
\hline & & No & 27.25 & 27.25 \\
\hline
\end{tabular}

The table above shows that most of the participants have experience feeling shame in food insecure households.

Both semi - structured interview and focus group discussion results support the quanitative results. According to the key informants, most of the children's in the food insecure household experience feeling shame or undermine themselves from their friends. Children labeled themselve as poor. This wrong thought leads children to have low self condfidance either to participate in the classroom activities or social participation with their peer groups (teachers).

Most of the children in poor household experience shyness, mistrusted in what they have dressed and what they have eaten $\&$ to be eat. Additionally, community labled children or their households as poor and being poor is attached with weakness and sometimes attached with inhertance problems. Some poor parents also teach their children being poor as a 
natural circumstance rather than siutuational. These are some of the suggested factors that contrbute children to develop feeling of shame(households in the FGD).

In the semi - structured interview a 14 years old child shares her experience as :'Look at, our family are poor. We have no enough food to eat. My friends labeled me as poor. And also I feel that even the other people in our neghibor undermine me. Therefore, I don't think I am equal with my friends in all aspects".

Consistent with above stetement a 13 years old child shares her experience during the interview as; "Always my friends take away what to eat in lunch time but I take nothing to eat. They always give me what to eat. This is the reason that I always feel fear because I have nothing to socially exchange or share all the time".

Table 6. Descripitive analysis of children's erxperience of interpersonal relationship

\begin{tabular}{|c|c|c|c|c|}
\hline No & Items & Response & Frequency & Percent \\
\hline \multirow{2}{*}{1} & \multirow{2}{*}{ There is a special person who is around me when I am in need } & Yes & 45 & 45 \\
\hline & & No & 55 & 55 \\
\hline \multirow{2}{*}{2} & \multirow{2}{*}{ There is a special person with whom I can share my joys and sorrows } & Yes & 21 & 21 \\
\hline & & No & 79 & 79 \\
\hline \multirow{2}{*}{3} & \multirow{2}{*}{ I have some neighbours who would help me out in a time of need } & Yes & 25 & 25 \\
\hline & & No & 75 & 75 \\
\hline \multirow{2}{*}{4} & \multirow{2}{*}{ I get the emotional help and support I need from my family } & Yes & 48 & 48 \\
\hline & & No & 52 & 52 \\
\hline \multirow{2}{*}{5} & \multirow{2}{*}{ My family really tries to help me } & Yes & 53 & 53 \\
\hline & & No & 47 & 47 \\
\hline \multirow{2}{*}{6} & \multirow{2}{*}{ I have friends with whom I can share my joys and sorrows } & Yes & 26 & 26 \\
\hline & & No & 74 & 74 \\
\hline \multirow{2}{*}{7} & \multirow{2}{*}{ I can talk about my problems with my friends } & Yes & 23 & 23 \\
\hline & & No & 77 & 77 \\
\hline \multirow{2}{*}{8} & \multirow{2}{*}{ Total ( Average) } & Yes & 34.43 & 34.43 \\
\hline & & No & 65.56 & 65.57 \\
\hline
\end{tabular}

The table above indicates that most of the participants have experience interpersonal relationship problems with their parents, peer groups (friends) and other siginificant person in their community or neighibors.

Participants involved in the semi-structured interview and focus group discussion revealed that most of children in food insecure households have no good relationship with their parents. This is because parenting style in food insecure household is more aggressive or autocratic type. This is the fact that children are forced to do things above their ability or capacity. And also parents are not give any credit for the children's work or efforts.

Additionally, the participants in the FGD agreed that in the community children in food insecure households have polluted name. Because most members of community negatively percieve the behaviors of children. Children's frequent conflict with their friends and suspected as criminals in the community are suggested reasons that affect community's attitude towards the children. This stigima and simple generalization or 'sterotype' alienate children from social relationship and pushed children to engage in anti social behaviors. It enhances children to feel inferiority or feel shame about what they have( households in the FGD).

Food problems in the households pushed children's to commit a crime and develop high need to engage in the anti social activities ( i.e gambling, robbery, stealing, hunging, etc). This is the reason that children have polluted name in the community and that shirnks their relationship with the fellow community members. Additionally, these are more discouraged children's interpersonal relationship with their peers and the community too (key informants).

Most of the young children in food insecure households encounter interpersonal relationship problems than older children. They experience it through shyness, alienating themselves from their peer groups, play grounds and develop fear to approach other persons (teachers).

Children participated in the interview indicated that children in poor households have no smooth relationship with their parents. Children attached different reasons to the problems. Basically, parental aggressive measures when the children violates parental norms. In similar with the children's thought parents involved in the interview and focus group discussion agreed that most of the children in poor households have poor relationship with their parents, peer groups and community rather than the children in food secure househlds.

During the sem - structured interview a 9 years old child shares his expierence as :"In our home there is no communication with our parents because our parents discourage our participation". This is the fact that most of the children have poor relationship with their friends.

In the interview a 13 years old child shares his experience 
as: 'I have no smooth relationship with my peer groups. This is because I spend most of my time by alone. My friends

insult me as poor or always labeled me as poor".

Table 7. Independant t - test analysis to observe differences in two age categories in experiencing aggeression, depression, feeling shame and interpersonal relationship

\begin{tabular}{lccccc}
\hline & Age & N & Mean score & St.devation & St. error \\
\hline \multirow{2}{*}{ Ageression } & $6-12$ & 49 & 5.4286 & 1.55456 & 0.22208 \\
& $13-18$ & 51 & 5.2353 & 0.76389 & 0.10697 \\
Depression & $6-12$ & 49 & 6.1837 & 0.75480 & 0.10783 \\
& $13-18$ & 51 & 6.7059 & 1.59115 & 0.22281 \\
Feeling shame & $6-12$ & 49 & 10.2449 & 1.03139 & 0.14734 \\
& $13-18$ & 51 & 10.1176 & 1.05161 & 0.14725 \\
Interpersonal relationship & $6-12$ & 49 & 11.5714 & 1.65831 & 0.23690 \\
& $13-18$ & 51 & 11.6078 & 1.70972 & 0.23941 \\
\hline
\end{tabular}

\begin{tabular}{|c|c|c|c|c|c|c|c|}
\hline & \multicolumn{7}{|c|}{$T$ - test of equality of means } \\
\hline & \multirow{2}{*}{$\mathbf{t}$} & \multirow{2}{*}{ df } & \multirow{2}{*}{ Sig (2-tailed) } & \multirow{2}{*}{ Mean difference } & \multirow{2}{*}{$\begin{array}{c}\text { St. error } \\
\text { difference }\end{array}$} & \multicolumn{2}{|c|}{$95 \%$ confidance interval of the difference } \\
\hline & & & & & & lower & upper \\
\hline \multirow{2}{*}{ Aggression } & 0.794 & 98 & 0.429 & 0.19328 & 0.24347 & 0.28989 & 0.67644 \\
\hline & 0.784 & 69.275 & 0.436 & 0.19328 & 0.24650 & 0.29844 & 0.68499 \\
\hline \multirow{2}{*}{ Depression } & -2.083 & 98 & 0.040 & -.52221 & 0.25071 & -1.01974 & -0.02468 \\
\hline & -2.110 & 72.048 & 0.038 & -.52221 & .24753 & -1.01964 & -.02878 \\
\hline \multirow{2}{*}{ Shamness } & .621 & 98 & .543 & .12725 & .20839 & -.29630 & .5408 \\
\hline & .611 & 97.957 & .543 & .12725 & .20831 & -.028614 & .54064 \\
\hline \multirow{2}{*}{$\begin{array}{l}\text { Interpersonal } \\
\text { relationship }\end{array}$} & -.108 & 98 & .914 & -.03641 & .33701 & -.70480 & .63238 \\
\hline & -.108 & 97.990 & .914 & -.03641 & .33681 & -.70480 & .63197 \\
\hline
\end{tabular}

The independant $\mathrm{t}-$ test for $(\mathrm{t}=0.794$ and sign $=0.429, \mathrm{t}$ $=-2.083$ and sign $=0.040, \mathrm{t}=-0.108$ and $\operatorname{sign}=0.914$, and $\mathrm{t}$ $=0.611$ and sign $=0.543$ aggression, depression, interpersonal relationship and feeling shame respectively ). The result indicates that $p$ value is greater than 0.05 for aggression and feeling shame. On the other hand, $\mathrm{p}$ value is less than 0.05 for depression and interpersonal relationship. Therefore, children in age between $6-12$ and $13-18$, there is stastically siginificant difference in internalizing behavior depression \& interpersonal relationship problems, while there is no staststically siginificant difference in experiencing behaviors like aggression and feeling shame.

The independant $\mathrm{t}$ - test descriptive analysis indicates that children under age 13 - 18 (5.4286) are more experiencing of depression problems than the younger children (10.2449). And children under age 13 - 18 (11.5711) are more experiencing of interpersonal relationship problems than the younger children ( 11.6078).

\section{Discussion}

\subsection{Children's Experience of Externalizing Behaviors: Aggression and Conduct Problems}

The first objective of this study is to assess children's experience of externalizing behaviors. The descrpitive and qualitative results reproduced that children in food insecure households experience various emotional and behavioral aggression; and misconduct behaviors that is matching with the previously identified study by Votruba - Drzal (2009). Various details were described to experess the experience of emotional and behavior aggression. These emotional hotness lead children to face conflict with their peer groups, neghibors, and the parents too. Poor children reflect in an elevated levels of externalizing behavioral problems, specially the problems of emotional aggression (Votruba Drzal, 2009; Kleinman, 1998; and Wright, 2010). The previous findings are consistent with the current finding in which children in food insecure households experience behavioral and emotional aggression. One possible explanation for the experience of this is when children skip meals, they have probability to develop angry and anxious emotions. These emotional expression sometimes push up children to express their behavior aggressively.Through the time children have great chance to condition the behavior.

So many factors are suggested to cause children's experience of emotional and behavioral aggression. However, the most repeatedly raised in the discussion were the occurance of the frequent conflict within the members of family in the home, and also the autocratic parenting style covers the Lion share. The food and finanical pressure at the home is suggested to lead parents to be more aggressive and forcing parents to take the aggressive measures on the their children. Hence, children imitate their parents behaviors and acts through observation. The current finding is consistent with the previous study by Slack (1938); and Shappard and Wiloughby, 1975) indicated that children do not do what 
adults tell to do, but they will model and imitate the real presentation of the real life of their parents through learning.

On the other extremes, children in poor households experience various conduct problems or anti - social behaviors. Children are engaged in the behaviors like ; murder or homicide, gambling, cheating, disrespecting elders, robbery and other criminal behaviors. This finding is consistent with the findings by Tomlinson (2008); Kelinman (1999); Griggs \& Walker (2008); and Liu (2004).

Different reasons are suggested to the children's experience of misconduct behavior in their households and community. Parental carelessness or irresponsable to handle or mange their childern's behavior is the suggested reason. . The poor parental mangement of children's behaviors contributes alot on the children's behavior to engage in criminal or anti - social behaviors. According to the "Family stress model' parental finanical problems exerts pressure on the parents to be more punitive, harsh and irresponsable to the childern's needs and activities (Magnuson \& Votruba Drzal, 2009).

Additionally, children in poor households are more experience school absentism and do not do their class activities and homeworks. Although some children in food secure households too experience misconduct behaviors in the school environments, it is difficult to say it is compareable with behaviors of children in food insecure households. This finding is consistent with the previously identified findings by Slack (2004). Different possible explanations are given. First, parents in food insecure households want children to be engage in income generating activities to help their efforts to fulifill food needs of their households. Because parents assume that it is impossible to gain daily meals or food through education. This is fact that most of children in food insecure households engeged in child labour. And parents do no encourage children to go school rather than helping them. Second, childern are also motivate to engage in different income generating activities rather than depending on the education. This is because children have an intention to be free from dependance on their parents and other siginificant persons to gain their daily meals. Finally, children are pessmistic about their future goals.

\subsection{Childern's Experience of Internalizing Behaviors: Depression and Feeling Shame}

The most suggested internalizing behavioral experiences includes feeling of anxiety, loneless, lack of concentration, feeling of sucide and insomina. This sympthoms are directily or indirectly attached with the experiences of depression. This reult is consistant with the pervious studies by (Belsky, 2010; Gunderses \& Kreider, 2009; and Purutcuoglu \& Hablemitoglu, 2002).

There are various explanations were given for the children's experiences of getting alone and feeling depression. First, inorder to escape from their peer groups scaring, children choose to be alone. Second, maternal depression in the household, frequent illness of children and their members of family, lack of dresses that is similar with their peers, parental conflict in the family, harsh or autocratic system of parenting and parental problems of attitude and finanicial shortage were considered as the major problems of children in food insecure households other than children in food secure households. The perivious study by (Beardsleg, Keller, Lavori, \& Adraian, qouted in Naylor, 2009) showed that maternal depresssion is a basic factor that push children's in food insecure households to experience depression.

Third, when children feel nothing to eat in their household, they are exposed to feel anxiety or stress. Children alaways compare themselves with their friends either in what they eat or they have dress. When they face dificulty to compare themselves with their peers, they are more exposed to experience depression. Finally, being pessimistic about the food problems in the households also exposed children to experience depression. This is to mean that children are hopeless and lack confidance in which the chronic food problems will be step down in near future in their households.

Feeling shame is the other internalizing behavioral problem that children in food insecure households experience. One possible explanation for the children's experience of feeling shame can be , frist, children feel that telling thier parents' socio - economic status to their peer groups will leads to social isolation and scaring. Because peer groups use this disadvantages of poor children's to insult or to alienate them from the frienship. Therefore, being keep silent or getting alone is the solution. This result is consistant with the perivious study by (Connell et al., 2005). The second explanation is that parents in poor households excluded themselves from the social relationship (i.e participating in ' Ikubi', 'Idir' and other social activities because of their economic demerits. This enforces children to feel their parents are 'poor', not equal with other member of neighbors and think to attach the shortage of food as natural.

The thrid explanation is that children in poor households model the daily experiences of their parents. Most of the parents in food insecure households exclude themeslves from the social relationship and from the social organizations. Because households have developed an attitude that they have nothing to gift to the social exchange and nothing to pay the membership fee for the social organizations. Due to these reasons households are exposed to feel shame or fear. Driectly or indirectly their children are forced to model their parents experience of shame. Childern in food insecure households were experience feeling of ashamed or fear, and developed social exclusion by observing their parental daily experience (Bronze - Tinkew et al., 2008).

\subsection{Children's Experience of Interpersonal Relationship}

Children's behavioral development depends on the adequate quality, perparation and consumption of healthy foods, interactive bonding and emtional and intellectual nurturance from the caregivers, supportive social and educational structures, and community, economic and political support ( Chilton et al., 2007 ). In additionally, Aber et al . (1997) indicated that children's interpersonal relationship is affected by the Bronfenbrenner's ecological 
systems ( i.e microsystem, macrosystem, mesosystem and exsosystem). Consistent with the previous studies and model, food insecurity affects children's interpersonal relationship with their parents, peer groups and community in general. There are varous explantions are given in children's experience of poor or weak interpersonal relationship.

Fristly, children in food insecure households are suspected as criminals in the community. Mainly commiting crimes particularly, participating in gambling, cheating, robbery, murder or homecide, stealing and disrespecting their elders in the community. Vilolation of these and other mores norms leads community to make discrimnation and stigam on the childern in the food insecure households. And the above childern's ways of behaving bitterly polluted children's name in the community. This is the fact that community members try to generalize the whole children in food insecure households as criminals and commiting crime or participating in the various types of anti social behaviors. This streotyped thoughts and attitudes of the community shrinks children's positive interaction with the community. Children in the opposite angle striving to revenge the community members' action through violation of the values and norms.

Secondly, children in poor households always scared and insulted by their peer groups as 'poor' or other forms of insults that bitterly damge childern's moral and psychological well being. To revange the actions of their peer groups, childern aggressively hurt their friends. This frequent conflict with their peer groups damage children's social and friendship interaction with their groups. And also these childern are suspected as stealing learning materials in the classrooms. The other related issue is that children face difficulty to practice social exchange with their peers. Thrid, parents' social, and economic resources can affect the quality and stability of their relationship with their children (Braveman et al., 2008). Children are not trusted on the caregivers. Because caregivers or parents didn't fulifill the basic needs of their children. Children are not obey for their parents. Finally, it is obvious that children are participating in different anti social behaviors and are not motivated to do their class activities and homeworks. This is the fact that children face conflict with their teachers and the school managements.

\section{Conclusion}

Children in food insecure households have the problems like aggressive behavior, misconduct behaviors or anti social behaviors (gambling, cheating, robbery,stealing and murder or homecide), depression, feeling shame, and poor or weak interpersonal relationship with their friends, parents and community too. Additionally, children have the problems like hot emotionality, insominia, stigima and discrimination, child labour and streotype. Older children $(13-18$ years old $)$ are more experience depressive behavioral and interpersonal relationship problems than younger children (6-12 years old). The autocratic parenting style, health problem in the family, frequent parental conflict among the members of the family, duties and responsibilities beyond the childern capacity, maternal depression, parental carelessness to carry out their parental roles, lack of dresses and child labour are the basic factors that expose children to the various types of psychological and social problems.

\section{Recommendations}

First, It is advisable that, govermental organizations and NGOs mobilize households to engage in different income generating activities to enhance the children's sustainable well being rather than heavely relying on food aids. Second, It is better if food aids are followed by psychosocial supports and cares for the children's \& their parents' to gurante children's physical and psychosocial well being. Third, to safe guard children's well being policy makers, governmental organizations, NGOs, researchers and other stakeholders advise to use the inclusive methods of children's care \& support strategies rather than relying merely on physical care \& support strategies. Fourth, it is difficult to modify children's misconduct behaviors by only using serious measures and penalties in the school, family and community. The problems need the experts' intervention. Therefore, the problems should be refere to the psychologists or other behavioral science experts. Finally, community and institutions based psychosocial cares and supports are more advisable to save children's sustanaible well being.

\section{Acknowledgments}

I would like to express my appreciation to my advisor Habtamu Wondmu (Proff) for his constructive comments and advices throughout the completion of this paper. My immense appreciation also goes to Silesh Zeleke (PhD), Ato Moges Ayele (lecture in AAU), Ato Daneil Tefera( lecture in AAU) and Daniel Haile (PHD, university of Chicago) for their academic support. And my friends, Abebayehu Tora (lecture in Woleyeta Sodo university), Zegeye paulos( Damot gale woreda food security, head), Seyuom Nigusse(Federal Minster of education consultant and special support expert for developing regions), and Asfaw Tora ( instructor in Woleyeta Sodo university) for their extremely help to finish this paper .I am also extremely grateful for my mom W/ro Tasame Tantu, my brothers Addisu and Melese for their financial and moral support.

\section{Strength}

It the original paper to addresses the psychosocial experiences of children in food insecure households. Using mixed approach has contributed its part for the strength of this paper.

\section{Weakness}

The result will be more smart if it is supported by 
longitudinal research design. Because of different reasons the investigator unable to use longitudinal design.

\section{References}

[1] Ahmed, Z. S. and Kingsolver, B. (2005). Poverty, family stress and parenting.

[2] Ahuja, Y. (2005). A critical review on the Bronfenbrenner's ecological theory of human behavioral development

[3] Alaimo, K., Olson, C. M. and Frongillo, E. A. (2001). Food in sufficiency and American school-aged children's cognitive, academic, and psychosocial development. Journal of the American academy of pediatrics, 108 (44), $1022-1049$.

[4] Amato, P. R. and Zcho, J. (1992). Rural poverty, urban poverty, and psychological well-being. The sociological quarterly journal, 33(2), $20-45$.

[5] Anderson, L. C., Ayalew Tegegn, Fusil Tessema, Galea, S. and Hadbey, C. (2010). Food insecurity, childhood illness and maternal emotional distress in Ethiopian.

[6] Andrews, B., Qian, M. and Valentine, J. D. (2002). Predicting depressive symptoms with a new measure of shame: The experience of shame scale. British Journal of clinical psychology, 41, 29- 42.

[7] Ashiabi, G . (2005). Household food insecurity and children's school engagement. Journal of children and poverty, 11:1, 3-17.

[8] Bacos F.F, Ramirez, R. M., Dorado, J. B., Velasco, R. E. and Barba, C. (2008). The nutritional Status of Street children why some are nutritionally well off or worst-off.

[9] Bechaye Tesfaye (2011). Rural household Food Insecurity Situation analysis: the case of Boricha Woreda, Sidama Zone.

[10] Belsky, D. B., Moffitt, T. E., Arseneault, L. A., Melchior, M. and Caspi, A. (2010). Context and sequelae of food insecurity in children's development. American Journal of Epidemiology, 72:809-818.

[11] Braveman, P., Sadegh-Nobari, T. and Egerter, S. (2003). Early childhood experiences: laying the foundation for health across a life time.

[12] Bronte - Tinkew, J., Zaslow, M., Capps, R., Horowitz, A. and McNamara, M. (2008). Food insecurity works through depression, parenting, and infant feeding to influence overweight and health in Toddlers. The journal of nutrition, $38(9), 214-252$.

[13] Brown, S. L. (2004). Family Structure, family processes, and adolescent delinquency: the absence of parental absence versus parental gender. Journal of research in crime and delinquency, 41 (1), $19-32$.

[14] Casey, P., Goolsby, S., Berkowitz, C., Frank, D., Gook, J., Cutts, D., Black, M. M., Zaldivar, N., Levenson, S., Heeren, T. and Meyers, A. (2004). Maternal depression, changing public assistance, food security, and child health status. Journal of American academy of Pediatrics, 113 (298), 46 - 69.

[15] Chant, S. (2006). Poverty Begins at home? Questioning some (mis) conceptions about children, poverty and privation in female-headed households. London school of economics.

[16] Cherry, K. (2004). Social learning theory: An Overview of
Bandura's Social learning theory.

[17] Child trands data Bank (2011). Food insecurity indicators on children and youth.

[18] Chilton, M., Chyatte, M. and Breaux, J. (2007). The negative effects of poverty and food insecurity on

[19] child development. Indian Journal of Medical research, 126, $68-91$.

[20] Collins, L. (2006). The Impacts of food insecurity on Women's mental health. How it negatively affects children's health and development. Journal of the Association for research on mothering, $56,574-588$.

[21] Conger, H. D. (2005). The effects of poverty and economic hardship across generations.

[22] Connel, C. L., LiLofton, K. L., Yadrick, K. and Rehnedr, T. A. (2005). Children's experiences of food insecurity can assist in understanding its effects on their well-being. Journal of nutrition 135: 1683-1690.

[23] Connell, C. L., Nord, M., Lofton, K. L. and Yadrick, K. (2004). Food security of older children can be assessed using a standardized survey instrument. The journal of nutrition, 134, $43-76$

[24] Cook, J. and Jeng, K. (2009). Child food insecurity: the economic impact on our nation. A report on the impact of food insecurity and hunger on child health, growth and development commissioned by feeding America and The ConAgra foods foundation. Chicago.

[25] Damot Gale Woreda Agricultural Office statistic report $(2010 / 11)$.

[26] Debabe Habtewolde (1995). Food security: a Brief Review of concerts and indicators. Proceedings of the inaugural and first annual conference of the agricultural economics society of Ethiopia.

[27] Degefa Tolosa (2005). Causes of seasonal food insecurity in Oromiya Zone of Amhara Region: Farmers'View: Department of Geography, Norwegian University of science \& Teachers. Degefa Tolosa (2002). Household seasonal food insecurity: Causes of social science Research report series.

[28] Denke Dana (2008). Population Pressure and its impacts of food security of rural households of Damot Woyde Woreda, Wolaita Zone.

[29] Dunifon, R. and Kowaleski-Jones, L. (2001). Associations between participation in the rational school Lunch program, Food insecurity, and child well-being.

[30] Emerson, E. N., Crowley, S. L., \& Merrell, K. W. (1994). Convergent validity of the school social behavior scales with the child behavior checklist and teacher's report form. Journal of psycho educational Assessment, 12, 372-380.

[31] Emery, R. E., Waldron, M., Kitzmann, K. M. and Aaron, J. (1999). Delinquent Behavior, culture divorce or non marital childrearing, and externalizing behavior among offspring: A 14 - year prospective study. Journal of family psychology, 13 (4), 1568-1579.

[32] Fields, J. M. and Smith, K. E. (1998). Poverty, Family structure, and child wellbeing. Population Division U.S Bureau of the Census Washington D.C. population division working papers, no. 23. 
[33] Feist, J. and Feist, G. (2008).Theories of personality. Seventh edition. McGraw_Hill, pp. $483-506$.

[34] Food and Agriculture Organization of the United Nations(2002).. The State of Food Security in the World, 4th edition. Available from $<$ http://www.fao.org $>$

[35] Grantham McGregor, S. (1995). A review of studies of the effects of severe malnutrition on mental development. Tropical Metabolism research unit. University of the West Indies. The journal of nutrition, 84(5), $431-450$.

[36] Griggs, J. and Walker, R. (2008). The costs of child poverty for individuals and society. Review paper.

[37] Gunderson, G. and Kreider, B. (2009). Bounding the effects of food insecurity on children's health outcomes. Journal of health economics, 74(6), $431-449$.

[38] Guide to Measuring households food security (2000 ). The United States Department of Agriculture.

[39] Haering, S. A. and Syed, S. B. (2009). Community food security in United states cities: A survey of the relevant scientific literature.

[40] Horgan, G. (2007). The impact of poverty on young children's experience of school. Joseph rowntree foundation. University of Ulster.

[41] Howard, L. L. (2010). Transitions between food insecurity and food predict children's social skill development during elementary school.

[42] Hvang, J., Karen, M., Oshima, M. \& Kim, Y. (2009). Does household food insecurity affect parental characteristics and child behavior? Evidence from the panel study of income dynamics (PSID). Social Service Review, 84(3), 381-401.

[43] Keegan, M. E. (2001). The effects of poverty on children's socio-emotional development: An ecological systems analysis. National association of social workers. Inc.

[44] Kiernan, K. E. and Hwertee, M. C. (2008). Economic deprivation, maternal depression, parenting and children's cognitive and emotional development in early childhood. The British Journal of Sociology, 59(47), 976 - 908.

[45] Kleinman, R. E., Murphy, J. M., Little, M., Pagano, M., Wehler, C. A., Regal, K. and Jellinek, M. S. (1998). Hunger children in the United States: Potential behavioral and emotional correlates. Journal of American academy of pediatrics, 101 (3), $76-94$.

[46] Kloep, M. and Tarifa, F. (1993). Linking economic hardship to families lives and children psychological wellbeing.

[47] Lawrence, J., Neil, A., Bennett, G., Conley, D. C. and Li, J. (1997). The effects of poverty on child health and development.

[48] Lilly, K. Y. (1998). Exploring the difficulties of stepmothers in the Hong Kong Chinese Society.

[49] Liu, J., Raine, A., Venables, P. H. and Mednick, S. A. (2009). Malnutrition at age 3 years and externalizing behavioral problems at age 8,11, and 17 years. The American Journal of Psychiatry, 31(4), $32-51$.

[50] Magnuson, K. and Vatruba- Drzal, E. (2009). Enduring influences of childhood poverty.
[51] Melchior, M., Caspi, A., Howard, L. M., Ambler, A. P., Bolton, H., Mountain, N. and Moffitt, T. E. (2009). Mental health context and food insecurity: a representative cohort families with young children. The journal of American academy of pediatrics, 62(2), $154-173$.

[52] McDonald, M. A., Sigman, M., Espinosa, M. P. and Neumann, C. G. (1994). Impact of a temporary food shortage on children and their mothers.

[53] Molcho, M., Gabhainn, S. N., Kelly, C., Friel, S. and Kelleher, G. (2005). Food poverty and health among school children in Ireland: findings from the health behavior in school aged children (HBSC) study.

[54] Mold, Z., Shariff, K. and Khor, G. L. (2008). Household food insecurity and coping strategies in a poor rural community in Malaysia. Nutrition Research and Practice, (2008), 2(1), 26-34.

[55] Naylor, B. T. (2009). Depression in children: Forms, causes and treatment. Nova science publishers, Inc. New York.

[56] Nord, M. (2009). Food insecurity in Households with children: Prevalence, severity, and household characteristics. Economic Information, Bulletin, V16.

[57] Paquette - John, D. R. (2001). Bronferbrenner's ecological system theory.

[58] Phipps, S. (2003). The impacts of poverty on health. Canadian institute of health information.

[59] Pilgrim, A., Barker, M., Jackson, A. and Ntani, G. (2011). Does living in a food insecure household impact on the diets and body composition of young children? Findings from the Southampton women's survey. Journal of epidemiological community health 56, $674-696$.

[60] Purutcuoglu, E. and Hablemitoglu, S. (2010). Interpersonal impact of poverty on children. International Journal of academic research, 2(6), $342-366$.

[61] Quandt, S. A., Shoaf, J. I., Japia, J., Hernandez - Pelletier, M., Clark, H. M. and Arcury, T. A. (2006). Experience of Latino Immigrant Families in North Carolina help explain elevated levels of food insecurity and hunger. The journal of nutrition, 28(8), $896-901$.

[62] Rabiee, F. (2004). Focus- group interview and data analysis. University of Central England. Proceedings of the Nutrition Society, 63, 655-660.

[63] Racine, E. F., Jemison, K., Huber, L. R. and Arif, A. A. (2008). The well-being of children in food insecure households: results from the eastern Caribbean child vulnerability study.

[64] Reid, k. (1997). The impacts of food insecurity on the children's well being. The journal of hunger and poverty, 56(6), 502- 538.

[65] Robinson, L. M., Mcintyre, L. and Officer, S. (2005). Welfare babies: Poor children's experiences informing healthy poor relationship in Canada. Health promotion international, vol.20 No. 4, pp. 362 - 390

[66] Rohde, B. (2003). The consequences of Hunger and Food insecurity for children: Evidence from recent scientific studies. Center on hunger and poverty Heller school for social policy and management. Brandeis University.

[67] Rohde, B. (2002). Psychosocial and behavioral impacts of food insecurity. 
[68] Rose-Jacobs, R., Black, M. M., Casey, P. H., Cook, J. T., Cutts, D. B., Chilton, M., Heeren, T., Levenson, S. M., Meyers, A. F. and Frank, D. A. ( ). Household food insecurity: association with at- risk infant and toddler development. Journal of pediatrics, 121(65), $256-278$.

[69] Rothman, E. F., Mandel, D. G. and Silverman, J. G. (2007). Abusers' perceptions of the effects of intimate partner violence on the children.

[70] Ryu, J . H. (2010). Indirect effects of food insecurity on psychosocial well being among school-aged children: evidence from ECLS-k. University of Wisconsin Madison

[71] Santrock, J. W. (2000). Introduction to childhood Psychology. Six edition.The McGraw-Hill companies. Pp. 208 \& 331.

[72] Schmidt, N. \& Sermat, V. (1983). Measuring loneliness in different relationships. Journal of Personality and Social Psychology, 44, 1038-1047.

[73] Shapiro, D. N. \& Stewart, J. (2011). Parenting stress, perceived child regard, and depressive symptoms among stepmothers and biological mothers. Journal of nervous mental disorders, 60(5), 533 - 544 .

[74] Slack, K. S. and Yoo, J. (2004). Food Hardships and child behavior problems among low-income children. Institute for research on poverty. University of Wisconsin- Madison.

[75] Slopen, N., Fitzmaurice, G., Williams, D. and Gilman, S. E. (2010). Poverty, food insecurity, and the internalizing and externalizing disorders. Journal of the American Academy of child and adolescent psychiatry, 49(5), 654 -668.

[76] Spencer, N. (2004). Does material disadvantage explain the increased risk of adverse health, education, and behavioral outcomes among children in lone parent households in Britain? Journal of epidemic community health, 59, 152-157.

[77] Tadelech Dalacho (1987). Socio-economic impacts of drought and the response of concern in Wolaita Awaraja with particular reference to Damot Wayde Woreda. A case study of 1984/85 Drought.

[78] Taylor - Powell, E. and Renner, M. (2003). Analyzing qualitative data. Program development and evaluation. University of Wisconsin.

[79] Tefera Belachew, Crogi Hadley, David Lindstrom, Abebe Gebremariam, Carl Lachat and Patrick Kolsteren(2011). Food insecurity, school absenteeism and educational attainments of adolescents in Jimma zone South Ethiopia: a longitudinal Study.
[80] Thorne, S. (2000). Data analysis in qualitative research. University of British Colombia Vancouver, British Columbia, Canada.

[81] Tomlinson, M., Walker, R. and Williams, G. (2008). The relationship between poverty and childhood well-being in Great Britain.

[82] UN Convention on the child rights (1990).

[83] U.S. Department of Agriculture(1999). U.S. Action Plan on Food Security, Solutions to Hunger. Available from $<$ http://www.fas.usda.gov>.

[84] Weinrel, L., Wehler, C., Perloff, J., Scott, R., Hosmer, D., Sager, L. and Gunderson, E. (2002). Hunger: Its impact on children's health and mental health. Journal of the American academy of pediatrics. 110(41), $981-1002$.

[85] Weissman, M. M., Qrvaschel, H., \& Padian, N. (1980). Children's symptom and social functioning self-report scales. Journal of nervous mental disorders, 168 (12): 736-740.

[86] Whitaker, R. C., Philips, S. M. and Orzol, S. M. (2006). Food insecurity and the risks of depression and anxiety in mothers and behavioral problems in their preschool-aged children- The journal of pediatrics, $98,534-563$.

[87] Wight, V. R., Thampi, K. and Briggs, J. (2010). Who are America's poor children? Examining food insecurity among children in the United States.

[88] Wolfe, W. S. and Frangillo, E. A. (2000). Building household food security measuring tools from ground up: Background paper.

[89] World Health Organization(2000).. "Nutrition Research: Pursuing Sustainable Solutions." Updated September 16, 2011. Available from $<$ http://www.who.int/en $>$

[90] Zamecnik, L. (2009). Canadian Women and Children hit hard by the impacts of food insecurity part one. Journal of hunger and poverty, 1(1), $23-46$.

[91] Zekeri, A. A. (2008). Food insecurity and emotional wellbeing among single mothers in rural south. The southern Rural Development Center Tuskegee University.

[92] Zimet, G. D., Dahlem, N. W., Zimet, S. G. \& Farley, G. K. (1988). The Multidimensional Scale of Perceived Social Support. Journal of Personality Assessment, 52, 30-41. 